Revista Electrónica de Investigación en Ciencias Económicas

Abriendo Camino al Conocimiento

Facultad de Ciencias Económicas, UNAN-Managua

\title{
LA COMUNIDAD ANDINA: UN PARADIGMA DE INTEGRACIÓN ECONÓMICA EN LATINOAMÉRICA
}

Jeanine Aguirre Ochoa ${ }^{1}$

Banco Procredit

1

Marco Aurelio Peña Morales

Programa MASTEPD

genius.marco24@gmail.com

Sonia Massiel Duarte Payán

Banco Procredit nineochoa@gmail.com

Fecha recepción: febrero 20 del 2014

Fecha aceptación: abril 5 del 2014

Palabras claves: Comunidad Andina;

Desarrollo; Integración; Libre

Comercio.

Key words: Andean Community, Development, Integration, Free Trade

ISSN: $2308-782 X$

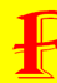

RE
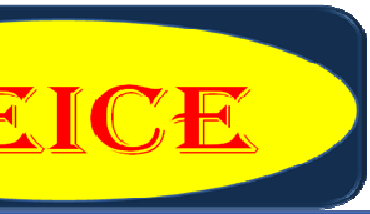

Revista Electrónica de Investigación en Ciencias Económicas

http://revistacienciaseconomicas.unan.edu.ni revistacienciaseconomicas@gmail.com revistarucfa@unan.edu.ni

\section{Resumen}

El presente trabajo tiene por objetivo reseñar los antecedentes, el estado actual y las perspectivas de futuro de la Comunidad Andina (CAN). Este bloque regional nació en 1969 con el nombre de Grupo Andino o Pacto Andino. Fue reformulado en 1997 dando origen a la

\footnotetext{
${ }^{1}$ Las autoras cursan el $2^{\circ}$ año de la maestría en

Economía Publica y del Desarrollo. UNAN-RUCFA
}

CAN, compuesta actualmente por Bolivia, Ecuador, Colombia y Perú como países miembros. Luego de establecerse formalmente como una Zona de Libre Comercio, en la que se fomentara un libre flujo de mercancías y personas, la CAN ha hecho todo lo posible por impulsar dinámicamente el comercio intracomunitario. El desarrollo del trabajo está sustentado en una base informativa de sitios web confiables y algunos libros textos. En esta investigación se ponen de relieve la filosofía comunitaria del bloque, los avances institucionales y económicos de la CAN, los proyectos de futuro y los desafíos que se avizoran, para finalmente dilucidar en qué etapa de su proceso de integración se encuentra y si se han obtenido los resultados previstos estratégicamente.

\section{Abstract}

This paper aims to review the history, current status and future prospects of the Andean Community (CAN). This regional bloc was born in 1969 with the name of the Andean Group and the Andean Pact. It was reformulated in 1997 giving rise to the CAN, currently composed of Bolivia, Ecuador, Colombia and Peru as members. After formally established as a Free Trade Zone, in which a free flow of goods and people be encouraged, CAN has done everything possible to dynamically boost intra. The development work is supported in an informative basis of reliable websites and some text books. This research highlights the communal philosophy of the box, institutional and economic developments of the CAN, future projects and challenges can be foreseen, to finally figure out what stage of the integration process is and whether they have obtained the expected results strategically. 
Revista Electrónica de Investigación en Ciencias Económicas

Facultad de Ciencias Económicas, UNAN-Managua

La Comunidad Andina: un paradigma de Integración Económica en Latinoamérica

Introducción

La Gran Recesión de 2008 ha obligado a los países adelantados a adoptar políticas y medidas que abarcan naturalmente el comercio y las finanzas internacionales; porque internacional ha sido la crisis desencadenada a finales de la primera década del tercer milenio. Mucha razón ha tenido el Premio Nobel 2008 Paul R. Krugman cuando discurrió en su libro Vuelta a la Economía de la Gran Depresión que por sorprendente que parezca, los monstruos de la economía como la recesión, la depresión, las devaluaciones astronómicas, la inflación, el desempleo y la estanflación han vuelto hacer su aparición cuando el mundo creía tener en sus manos las herramientas y el conocimiento suficientes para evitar y conjurar cualquier crisis económica; sin embargo no ha sido así.

En este contexto, los gobiernos de los países latinoamericanos también adoptaron sus propias políticas y medidas, las cuales han sido recogidas en un documento electrónico disponible en la página web de la CEPAL titulado La Reacción de los Gobiernos de las Américas frente a la Crisis Internacional. Como efecto inmediato de la crisis económica, cayeron significativamente los volúmenes de exportación de las economías latinoamericanas cuyos principales socios comerciales han sido Estados Unidos de América y la Unión Europea. La situación crítica fue propicia para que los países de América Latina reforzaran sus procesos de integración y tomaran conciencia más que nunca de lo trascendental que es constituirse en un bloque regional frente al resto del mundo con el fin de tener más peso en la economía mundial en tiempos de prosperidad y en tiempos de crisis. El caso que se aborda en el presente trabajo como referencia de proceso de integración y bloque regional es el de la Comunidad Andina (CAN) o Sistema Andino de Integración (SAI).

El presente trabajo sobre la Comunidad Andina se propone remontarse a sus antecedentes, esbozar su estado actual y poner de manifiesto cuáles son sus perspectivas. Se observa el comportamiento de este proceso de integración tanto en lo económico como en lo jurídico-institucional. La CAN con 44 años de edad -que cuenta con países socios y observadores- es un caso que puede facilitarle a América Central lecciones valiosas sobre integración política y económica, puesto que el Sistema de Integración Centroamericana (SICA), a pesar de sus antecedentes y sus años, no ha avanzado a un ritmo plenamente satisfactorio.

No es casualidad que el Informe sobre Desarrollo Humano 2013 del PNUD se titule El ascenso del Sur: Progreso humano en un mundo diverso. Es enriquecedor estudiar cómo algunas economías suramericanas se han vuelto paradigmas de desarrollo e integración, y la Comunidad Andina es una experiencia audaz de 4 países (con raíces ancestrales comunes) que tomaron la decisión de unirse como bloque regional buscando insertarse cada vez más en la vertiginosa economía global. 
Revista Electrónica de Investigación en Ciencias Económicas

Facultad de Ciencias Económicas, UNAN-Managua

La Comunidad Andina: un paradigma de Integración Económica en Latinoamérica

Material y métodos

Para la realización del presente trabajo investigativo se ha utilizado una metodología ampliamente informativa, expositiva y descriptiva, siendo por regla especial analítica y crítica cuando el caso lo amerita. La disquisición va deductivamente de lo general a lo particular. Cada punto es abordado sucintamente pero sin sacrificar sistematicidad ni contenido. Se ha aplicado en gran manera un método de síntesis a la densa bibliografía existente.

El desarrollo del trabajo está sustentado en una base informativa de sitios web confiables y algunos libros textos. Se apostó más por la información digital que por la información impresa ya que lo digital tiene la ventaja de actualizarse con mucha más rapidez que lo impreso. Se ha ilustrado el cuerpo de la investigación con algunas figuras y gráficas. Las gráficas son elaboración propia de los autores sobre la base de datos oficiales. La naturaleza del tema objeto de investigación y los modestos objetivos trazados no permitían hacer un examen más exhaustivo y holístico.

\section{Resumen y Discusión}

La Comunidad Andina (CAN) es una comunidad de cuatro países suramericanos unidos por el objetivo común de alcanzar un desarrollo integral, más equilibrado y autónomo, mediante la integración andina, suramericana y latinoamericana. El proceso andino de integración se inició con la suscripción del Acuerdo de Cartagena el 26 de mayo de 1969.

Los países miembros de la comunidad son Bolivia, Colombia, Ecuador y Perú. Estos países ocupan aproximadamente la cuarta parte del subcontinente sudamericano y albergan a más de 100 millones de habitantes. Adicionalmente, la CAN cuenta con los países del Mercado Común del Sur (MERCOSUR) ${ }^{2}$ como miembros asociados desde el 7 de julio de 2005 por decisión del Consejo Andino, y con cuenta con dos países observadores: México y Panamá.

La integración andina se define como un proceso que tiene como fin el logro de los objetivos establecidos en el Acuerdo de Cartagena. En tal sentido, se prevé una evolución caracterizada por el perfeccionamiento, procurando un mejor uso de los factores productivos y de los recursos para alcanzar una mayor eficiencia económica y una mejora en el nivel de vida de los habitantes de sus países miembros.

\footnotetext{
${ }^{2}$ El Mercado Común del Sur (MERCOSUR) está compuesto por Brasil, Argentina, Paraguay y Uruguay.
} 
Revista Electrónica de Investigación en Ciencias Económicas

Facultad de Ciencias Económicas, UNAN-Managua

La Comunidad Andina: un paradigma de Integración Económica en Latinoamérica

La CAN pretende contribuir al desarrollo equilibrado y armónico de los países miembros, evitando desigualdades de desarrollo entre cada país miembro. El acuerdo creador de la CAN es un esquema regulador que interviene en las economías para propiciar una distribución equitativa de los beneficios derivados de la integración, de forma coherente, realista y transparente. Cabe destacar que se reconoce la existencia de distintas velocidades en la aplicación de los mecanismos que propone el Acuerdo de Cartagena para cada miembro. Los países miembros reconocen la necesidad de disminuir gradualmente las diferencias de desarrollo existentes en la subregión; por esta razón, se otorga un tratamiento especial y diferenciado a Bolivia y Ecuador.

La definición de políticas públicas de integración se lleva a cabo mediante un esquema intergubernamental, ya que son los gobiernos quienes tienen la función de orientar su accionar y adoptar la normativa que desarrolla y regula la instrumentación de las medidas e instrumentos del acuerdo. No obstante, se reconoce al sector privado como actor principal, dado que las operaciones económicas las lleva a cabo la empresa privada, y se ve a la sociedad civil como un aliado sustancial de consulta y asesoría.

Los objetivos de la Comunidad Andina se pueden resumir en los siguientes:

- Promover el desarrollo equilibrado y armónico en condiciones de equidad, mediante la integración y la cooperación económica y social.

- Acelerar el crecimiento y la generación de empleo.

- Facilitar la participación de los países miembros en el proceso de integración regional, con miras a la formación gradual de un mercado común latinoamericano.

- Mejorar la posición de los países miembros en el contexto económico internacional.

- Fortalecer la solidaridad subregional y reducir las diferencias de desarrollo existentes entre los países miembros.

- Procurar un mejoramiento persistente en el nivel de vida de los habitantes de la subregión. 


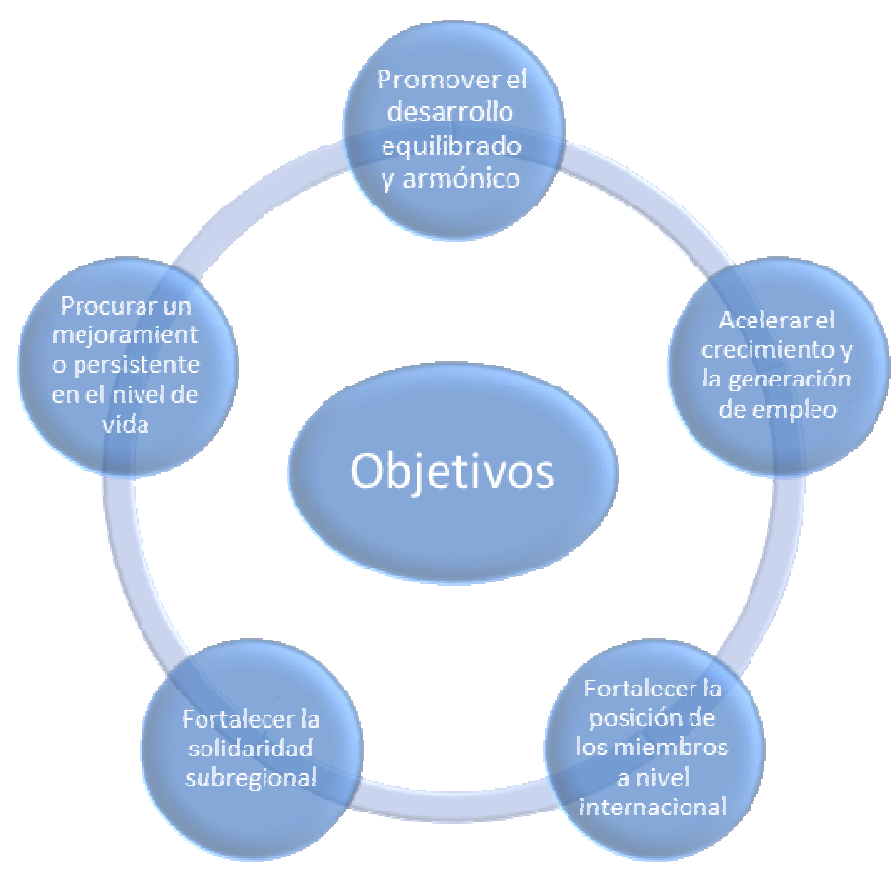

REICE | 5

Figura No. 1: Objetivos de la CAN

Fuente: Elaboración propia

Antecedentes: La llamada zona andina de Sudamérica se ha caracterizado por un clima desértico en la costa, parajes altiplánicos y profundas junglas en el interior. Los primeros pobladores de esta zona se vieron en la necesidad de construir diversas comunidades, que con el tiempo formarían complejas culturas; siendo una de las más conocidas el Imperio Inca, cuyos dominios se extendieron desde Pasto en Colombia por el Norte, hasta Talca en Chile por el Sur, incluyendo regiones de las actuales naciones de Argentina, Ecuador, Perú y Bolivia.

Al llegar los españoles, el Imperio se dividiría en múltiples colonias, siendo la más importante la del Virreinato del Perú, que después de la independencia, se dividió a su vez en varias naciones. Ya para los tiempos del movimiento independentista, el Libertador Simón Bolívar intentaría infructuosamente la creación de una Gran Colombia a partir de la unificación de Venezuela, Ecuador y Nueva Granada (la actual Colombia). Un posterior intento de reunificación del Perú y el Alto Perú (Confederación Perú-Boliviana) alcanzó a durar 3 años, hasta ser disuelta por Chile y Argentina en 1839. Este sería el último intento de crear una nación andina tomando como base los antiguos territorios del Imperio Inca. 
Revista Electrónica de Investigación en Ciencias Económicas

Facultad de Ciencias Económicas, UNAN-Managua

La Comunidad Andina: un paradigma de Integración Económica en Latinoamérica

Los antecedentes de la Comunidad Andina se remontan al 26 de mayo de 1969, cuando Bolivia, Colombia, Chile, Ecuador y Perú (países con raíces ancestrales comunes) firmaron el Acuerdo de Cartagena, también conocido como Pacto Andino, con el propósito de establecer una unión aduanera en un plazo de diez años. Este acuerdo se firmó con el propósito de mejorar el nivel de vida de sus habitantes, mediante la integración y la cooperación económica y social. Más adelante, la CA ganaría un país miembro cuando el 13 de febrero de 1973 Venezuela se adhirió; sin embargo perdería uno cuando el 30 de octubre de 1976 Chile se retiró.

La CAN ha atravesado por distintas etapas. De una concepción básicamente cerrada de integración hacia adentro, acorde con el modelo de sustitución de importaciones (predominante en los 70's), se reorientó hacia un esquema de regionalismo abierto a finales de los ochenta. En la reunión de Galápagos (1989), los mandatarios andinos aprobaron el diseño estratégico y el plan de trabajo donde se plasmó el nuevo modelo, con el cual los países miembros eliminaron entre sí los aranceles y formaron una zona de libre comercio en 1993 en la que las mercancías circularan libremente. El comercio intracomunitario creció vertiginosamente y se generaron miles de empleos. Se liberalizaron también los servicios, especialmente de transporte en sus diferentes modalidades.

Los cambios registrados en la economía mundial plantearon nuevos retos que exigieron la introducción de reformas en el Acuerdo de Cartagena, tanto de carácter institucional como estructural. Fue entonces como se signaron el Protocolo de Trujillo y el Protocolo de Sucre. Producto de estas reformas se creó en 1997 la Comunidad Andina en reemplazo del Pacto Andino.

A partir del 1 de agosto de 1997 inició sus funciones la Comunidad Andina con una secretaría general de carácter ejecutivo, cuya sede está en Lima (Perú). Se formalizó también el establecimiento del Consejo Presidencial Andino y del Consejo Andino de Ministros de Relaciones Exteriores como nuevos órganos de orientación y dirección política. Se amplió además el papel normativo de la Comisión, integrada por los ministros de comercio, a los ministros sectoriales. Con las reformas institucionales también se creó el Sistema Andino de Integración (SAI), dándole al proceso una dirección política que amplió el campo de la integración más allá de lo puramente comercial y económico.

Con el tiempo se observó que a pesar de las reformas y el crecimiento económico experimentado, los niveles de pobreza no se reducían. En consecuencia, en el año 2003 se estableció por mandato presidencial el Plan Integrado de Desarrollo Social y poco a poco se fueron retomando los temas de desarrollo que estuvieron presentes en los inicios del proceso de integración. 
Revista Electrónica de Investigación en Ciencias Económicas

Facultad de Ciencias Económicas, UNAN-Managua

La Comunidad Andina: un paradigma de Integración Económica en Latinoamérica

El 22 de abril de 2006 Venezuela formalizó su decisión de denunciar el Acuerdo de Cartagena y el 9 de agosto del mismo año suscribió con los países miembros de la Comunidad Andina un memorando de entendimiento, por medio del cual acordaron dar plena vigencia a las ventajas comerciales recibidas y otorgadas de conformidad con el programa de liberación de la subregión andina, que debe mantenerse entre las partes. La separación de Venezuela se debió a al manifestar sus desavenencias con Perú y Colombia por haber firmado estos dos países andinos tratados de libre comercio con EUA.

El 20 de septiembre de 2006, mediante la Decisión No. 645 del Consejo de Ministros de Relaciones Exteriores y de la Comisión, se le otorgó a Chile la condición de país miembro asociado de la Comunidad Andina. Igualmente, las naciones del MERCOSUR, por disposición de la Decisión No. 613, ostentan la calidad de miembros asociados desde el 7 de julio de 2005. La Comunidad Andina a su vez es miembro asociado del MERCOSUR.

En 2007, en la Cumbre de Tarija, los presidentes de los países de la Comunidad Andina acordaron impulsar una integración integral que propugna un acercamiento más equilibrado entre los aspectos sociales, culturales, económicos, políticos, ambientales y comerciales.

Actualmente, las acciones de los países de la Comunidad Andina se guían por los Principios Orientadores y la Agenda Estratégica aprobados en 2010, así como su Plan de Implementación. En julio de 2011, en la Cumbre de Lima, los Presidentes de Bolivia, Colombia, Ecuador y Perú acordaron fortalecer y dar un renovado dinamismo al proceso andino de integración, para lo cual dispusieron emprender un proceso de revisión de la estructura institucional y funcionamiento del Sistema Andino de Integración (SAI). En noviembre de ese mismo año, en la Cumbre de Bogotá, ratificaron dicho acuerdo. Como sumatoria de todo el esfuerzo de años, la Comunidad Andina es hoy una organización subregional con personería jurídica internacional integrada por Bolivia, Colombia, Ecuador y Perú, con países socios y países observadores.

Desafíos políticos: El ambicioso objetivo de implementar una política exterior común data de 1998. Este objetivo apunta a adoptar posiciones comunes, e incluso a armonizar las políticas extranjeras, pero no se han logrado resultados concretos hasta el momento. Por ejemplo, Colombia fue la única que apoyó la acción militar de Estados Unidos en Irak a partir de febrero de 2003.

Un acuerdo sobre la consolidación de los principios democráticos generó la firma de varios protocolos sobre el ejercicio de la democracia. En caso de ruptura del orden 
Revista Electrónica de Investigación en Ciencias Económicas

Facultad de Ciencias Económicas, UNAN-Managua

La Comunidad Andina: un paradigma de Integración Económica en Latinoamérica

democrático en un país miembro, pueden aplicarse sanciones como por ejemplo la exclusión de las instituciones, la suspensión de proyectos o de préstamos. Sin embargo, las dificultades políticas internas que, en diversos grados, afectan a los países miembros de la organización, no allanan el camino hacia la integración política.

REICE | 8

Particularidades de la Comunidad Andina

El Sistema Andino de Integración, está conformado por los siguientes órganos e instituciones directores:

Organizaciones Intergubernamentales

$\checkmark$ Consejo Presidencial Andino: es el máximo órgano del Sistema Andino de Integración (SAI) que ejerce la dirección sobre decisiones políticas. Emite directrices que son instrumentadas por los órganos que lo conforman.

$\checkmark$ Consejo Andino de Ministros de Relaciones Exteriores: es el órgano legislativo y de decisión encargado de formular y ejecutar la política exterior de los países miembros en asuntos que sean de interés subregional. Coordina la acción externa de los órganos e instituciones del SAl.

Comisión de la Comunidad Andina: está constituida por un representante plenipotenciario de cada uno de los Gobiernos de los países miembros. Es otro de los órganos normativos del Sistema Andino de Integración cuya capacidad legislativa es expresada en la adopción de Decisiones, especialmente vinculadas con comercio e inversiones.

\section{Organizaciones Comunitarias}

$\checkmark$ Tribunal de Justicia Andino: es de carácter permanente, supranacional y comunitario. Fue instituido para declarar la legalidad del derecho comunitario y asegurar su interpretación y aplicación uniforme en todos los países miembros. Tiene su sede en Quito (Ecuador).

Parlamento Andino: es el órgano comunitario deliberante del Sistema; representa a los pueblos de la Comunidad Andina y está constituido por representantes elegidos por sufragio universal y directo. Funciona en la ciudad de Bogotá (Colombia) con carácter permanente.

Secretaría General: es el órgano ejecutivo y técnico de la Comunidad Andina y en tal carácter actúa únicamente en función de los intereses de la subregión. Tiene su sede permanente en Lima (Perú). 
Revista Electrónica de Investigación en Ciencias Económicas

Facultad de Ciencias Económicas, UNAN-Managua

La Comunidad Andina: un paradigma de Integración Económica en Latinoamérica

Banco de Desarrollo de América Latina: es una institución financiera constituida en 1970 que impulsa el desarrollo sostenible y la integración regional de América Latina mediante operaciones de crédito, recursos no reembolsables y apoyo en la estructuración técnica y financiera de proyectos de los sectores públicos y privados. Tiene su sede en Caracas (República Bolivariana de Venezuela).

REICE | 9

$\checkmark$ El Fondo Latinoamericano de Reservas: trabaja por la estabilidad de los países miembros al mejorar su posición externa y fortalecer la solidaridad regional. Tiene su sede en Bogotá (Colombia).

$\checkmark$ Organismo Andino de Salud Convenio Hipólito Unanue: es la institución que coordina y apoya las acciones que realizan los países miembros, individual o colectivamente, para el mejoramiento de la salud de sus pueblos. Tiene su sede en Lima (Perú),

Universidad Andina Simón Bolívar: es la institución educativa del Sistema Andino de Integración, dedicada a la investigación, la enseñanza, la prestación de servicios, especialmente para la transmisión de conocimientos científicos y tecnológicos, y al fomento del espíritu de cooperación y coordinación entre las universidades de la subregión, así como al fortalecimiento de los principios de la Comunidad Andina.

Instancias de Participación de la Sociedad Civil

$\checkmark$ Consejo Consultivo Empresarial: es una institución consultiva que busca promover una mayor participación del sector empresarial en el proceso andino de integración.

$\checkmark$ Consejo Consultivo Laboral: es una institución consultiva cuya función es la de emitir opinión ante el Consejo Andino de Ministros de Relaciones Exteriores, la Comisión o la Secretaría General.

$\checkmark$ Consejo Consultivo de Pueblos Indígenas: es una instancia consultiva que busca promover la participación activa de los pueblos indígenas en los asuntos vinculados a la integración subregional.

$\checkmark$ Consejo Consultivo Andino de Autoridades Municipales: es una institución consultiva orientada a impulsar acciones que fortalezcan las ciudades y los gobiernos locales como actores de la integración.

Mesa Andina para la Defensa de los Derechos del Consumidor: es una instancia consultiva para promover la activa participación de las instituciones públicas y privadas, vinculadas con la defensa de los derechos del consumidor en los países miembros de la Comunidad Andina. 


\author{
Revista Electrónica de Investigación en Ciencias Económicas \\ Facultad de Ciencias Económicas, UNAN-Managua \\ La Comunidad Andina: un paradigma de Integración Económica en Latinoamérica
}

$\checkmark$ Mesa del Pueblo Afrodescendiente de la Comunidad Andina: es una instancia consultiva para promover la activa participación de las organizaciones representativas del pueblo afrodescendiente en los asuntos vinculados con la integración subregional.

La finalidad del Sistema Andino de Integración (SAI) es permitir una coordinación efectiva entre todos los órganos e instituciones para profundizar la integración andina, promover su proyección externa y robustecer las acciones relacionadas con el proceso. Con el fin de lograr la mejor coordinación del SAI, el Presidente del Consejo Andino de Ministros de Relaciones Exteriores convoca y preside la reunión de representantes de las instituciones que conforman el Sistema, la cual se realiza al menos una vez al año y, en forma extraordinaria, cada vez que lo solicite cualquiera de sus instituciones integrantes.

El SAI articula también otros órganos e instituciones creados en el marco de la integración subregional andina, tales como los Consejos Asesores Ministeriales que emiten opinión ante el Consejo Andino de Ministros de Relaciones Exteriores y la Comisión sobre temas relacionados a su sector, además de Comités Técnicos.

Los principales logros de este acuerdo se resumen a continuación, y se condensan en el art. 3 del Acuerdo de Cartagena (El orden de presentación corresponde al de aparición en el mencionado artículo y no necesariamente a su importancia):

Relaciones Externas: La Comunidad Andina cuenta con lineamientos que orientan su Política Exterior Común (PEC), en la cual, en lo económico, se contempla la promoción comercial y de las inversiones con la finalidad de difundir las oportunidades comerciales y de servicios y promover, sobre la base de la normativa comunitaria, la acción conjunta en los foros de negociación multilateral, así como con otros esquemas de integración en la región.

La Comunidad Andina le otorga prioridad a todas las acciones que apoyen el fortalecimiento de estadios ampliados de integración regional suramericana y en América Latina -como son la Unión de Naciones Suramericanas (UNASUR) y la Comunidad de Estados Latinoamericanos y Caribeños (CELAC)-, propendiendo hacia la complementariedad, la eficiencia en la gestión multilateral, y la cooperación entre los diversos mecanismos, grupos y foros de concertación e integración regionales. Asimismo, le otorga gran importancia tanto a la asociación recíproca de los países miembros de la Comunidad Andina con aquellos del Mercado Común del Sur (MERCOSUR) y a una proyección de convergencia suramericana, como a los Acuerdos de Complementariedad Económica celebrados en el marco de la Asociación Latinoamericana de Libre Comercio (ALADI). 


\author{
Revista Electrónica de Investigación en Ciencias Económicas \\ Facultad de Ciencias Económicas, UNAN-Managua \\ La Comunidad Andina: un paradigma de Integración Económica en Latinoamérica
}

Mercado Ampliado de Bienes

\title{
- Comercio de Bienes
}

Una vez alcanzado el objetivo de contar con una zona de libre comercio entre los países de la CAN, ahora se busca perfeccionar la normativa que rige dicho mercado ampliado e impulsar acciones que contribuyan a la transparencia y facilitar el libre flujo de mercaderías.

Con tal fin, la CAN tiene el compromiso de no establecer gravámenes ni restricciones que afecten las importaciones intrasubregionales. La Secretaría General de la CAN se encarga de velar por el cumplimiento del Programa de Liberación. Para ello, realiza investigaciones y, mediante resoluciones, determina si las medidas que adoptan los países miembros se constituyen o no en gravámenes o restricciones a las importaciones intrasubregionales.

Adicionalmente, se desarrollan acciones con miras a la facilitación del comercio, la libre circulación y el aprovechamiento pleno del mercado ampliado andino, manteniendo actualizada la Nómina de Bienes No Producidos (NBNP) y estableciendo los precios de referencia de los productos que conforman el Sistema Andino de Franjas de Precios (SAFP). Se destaca la acción de implementación y puesta en marcha del sistema informático del Arancel Integrado Andino (ARIAN), así como las de asistencia técnica a los países miembros en sus sistemas de información de comercio.

\section{- Normas de Origen}

El Programa de Liberación Andino garantiza el libre comercio, es decir la eliminación de gravámenes o restricciones de todo orden, para aquellos bienes calificados como originarios de un país miembro. El origen de una mercancía elaborada en un país miembro se evalúa en función a las disposiciones vigentes en el marco comunitario. En ese sentido, la CAN cuenta con la Decisión 416, mediante la cual se establecen los criterios generales que deben cumplir las mercancías para ser consideradas como originarias de un país miembro y, luego de ello, beneficiarse de las ventajas que le otorga el mercado ampliado.

\section{- Aduanas}

La CAN ha aprobado una serie de instrumentos legales que permitan a las Administraciones Aduaneras de los países miembros desarrollar los servicios aduaneros tanto en el comercio intracomunitario como con terceros países, bajo un procedimiento común y armonizado acorde con los instrumentos y estándares internacionales que existen sobre la materia, teniendo como objetivo la facilitación del comercio exterior y mejora de la eficiencia de las medidas destinadas al cumplimiento de la legislación y el control aduanero. 


\author{
Revista Electrónica de Investigación en Ciencias Económicas \\ Facultad de Ciencias Económicas, UNAN-Managua \\ La Comunidad Andina: un paradigma de Integración Económica en Latinoamérica
}

Entre estos instrumentos se encuentra la nomenclatura común (NANDINA) que tiene como propósito facilitar la identificación y clasificación de las mercancías, las estadísticas de comercio exterior y otras medidas de política comercial de la CAN relacionadas con la importación y exportación. Las normas andinas sobre regímenes aduaneros permiten la armonización de los procedimientos y formalidades exigibles en el ingreso y salida de las mercancías y medios de transporte, así como en la destinación aduanera de las mercancías a un régimen u operación aduanera, habiéndose adoptado a nivel andino el Documento Único Aduanero (DUA).

EI ARIAN es un sistema que permite recoger, validar e incorporar a una base de datos toda la información y normativa que generan los órganos de decisión de la Comunidad Andina, mediante las aperturas, en los casos en que sea necesario, de las subdivisiones de la Nomenclatura Común Andina (NANDINA), para designar las mercancías que sean objeto de reglamentaciones específicas. Por su parte, las normas andinas de valoración permiten a los países miembros contar con una normatividad común para la determinación de la base imponible de los derechos de aduana e impuestos aplicables en la importación de mercancías, contando para ello con una Declaración Andina del Valor (DAV), la cual brinda información sobre la transacción comercial.

El régimen normativo sobre Tránsito Aduanero Comunitario permite trasladar, bajo una misma operación, mercancías desde la Aduana de un país miembro a la Aduana de otro país miembro, atravesando una o varias fronteras de los países miembros. Esta área se complementará con el proyecto de Tránsito Internacional de Mercancías (TIM) que permitirá su automatización, la implementación de la figura del Operador Económico Autorizado Andino, perfeccionar el sistema de información que soporta el sistema andino de valoración aduanera y el equipamiento de los laboratorios químicos de las aduanas.

\title{
- Política Arancelaria
}

Los países miembros se comprometieron, desde el inicio de la integración andina, a contar con un Arancel Externo Común (AEC) en los plazos y modalidades que establezca la Comisión. No existiendo dichas condiciones, se dispuso la creación de un Grupo de Trabajo de Alto Nivel de Política Arancelaria encargado de recomendar a la Comisión proyectos de decisión con miras al establecimiento de una Política Arancelaria de la Comunidad Andina que incorpore a todos los países miembros.

En 2011, los países miembros de la CAN acordaron extender la suspensión de la aplicación de la normativa comunitaria sobre AEC y disposiciones complementarias hasta finales de 2014. 


\author{
Revista Electrónica de Investigación en Ciencias Económicas \\ Facultad de Ciencias Económicas, UNAN-Managua \\ La Comunidad Andina: un paradigma de Integración Económica en Latinoamérica
}

\title{
- Defensa Comercial
}

La circulación de los bienes sin pago de gravámenes es el principio rector que rige las relaciones comerciales en la CAN; sin embargo, los países miembros acordaron incluir dentro de su política comercial comunitaria la posibilidad de contar con determinados instrumentos que le permitan a cualquiera de ellos atender, en ciertos casos debidamente calificados, los efectos dañinos que pudieran devenir de esta relación comercial.

Para tales casos, el Capítulo XI del Acuerdo de Cartagena establece las normas y procedimientos generales para la aplicación de salvaguardias, para 4 tipos de salvaguardia (Balanza de Pagos, Programa de Liberación, Productos Específicos, Devaluación Monetaria). Se dispone de una norma comunitaria para corregir distorsiones a la competencia por diferencias arancelarias entre Perú y los demás países miembros, y otra sobre las restricciones a las exportaciones intracomunitarias.

\section{Política de Competencia y Consumidores}

Con el objetivo de buscar el bienestar de los consumidores y la eficiencia en los mercados, desde marzo de 2005, la Comunidad Andina cuenta con una norma comunitaria que contiene las reglas para proteger y promover la libre competencia en el mercado ampliado. Esta decisión comunitaria identifica el tipo de conductas que considera restrictivas de la libre competencia y establece las facultades de la Secretaría General para realizar investigaciones relacionadas con la libre competencia. Asimismo, la decisión andina tiene por objeto la adopción y aplicación de políticas de promoción de la libre competencia entre los países andinos.

\section{Sistema Andino de Calidad}

La CA dispone además de un Sistema Andino de Normalización, Acreditación, Ensayos, Certificación, Reglamentos Técnicos y Metrología, denominado Sistema Andino de la Calidad, que tiene como objetivo propiciar una mayor fluidez del comercio intracomunitario a través de la eliminación de los obstáculos técnicos innecesarios, y de la mejora de la calidad de los bienes que se producen en la subregión andina.

Este sistema tiene como ámbito de aplicación todos los productos de la subregión, con excepción de las medidas sanitarias y fitosanitarias u otras reguladas por una decisión específica. Este Sistema es administrado por el Comité Subregional de Normalización, Acreditación, Ensayos, Certificación, Reglamentos Técnicos y Metrología (denominado Comité Andino de la Calidad - CAC). 


\author{
Revista Electrónica de Investigación en Ciencias Económicas \\ Facultad de Ciencias Económicas, UNAN-Managua \\ La Comunidad Andina: un paradigma de Integración Económica en Latinoamérica
}

Sanidad Humana

Una preocupación fundamental del proceso andino de integración es el de la salud humana, para lo cual se considera indispensable regular el comercio de ciertos bienes a fin de evitar que se atente contra la salud de las personas (por ejemplo: la inocuidad de los alimentos). Los bienes que se trancen no tienen que significar una amenaza para la salubridad de las personas en cada uno de los países miembros. Existe normativa que viene a regular este aspecto (por ejemplo: la regulación de productos de higiene y belleza personal).

\title{
Sistema Andino de Sanidad Agropecuaria
}

La Comunidad Andina tiene un marco jurídico para la adopción de medidas sanitarias y fitosanitarias de aplicación al comercio intrasubregional y con terceros países sobre plantas, productos vegetales, artículos reglamentados, animales y sus productos. Dicho marco jurídico fue adoptado en marzo de 2002 mediante la Decisión 515, que crea el Sistema Andino de Sanidad Agropecuaria (SASA), el cual establece sus objetivos, su institucionalidad y sus instrumentos, y las características de las normas sanitarias y fitosanitarias, su registro, entre otros.

La norma define el SASA como el conjunto de principios, elementos e instituciones, que se encarga de armonizar las normas sanitarias y fitosanitarias; y de proteger y mejorar la sanidad animal y vegetal; contribuir al mejoramiento de la salud humana; facilitar el comercio de plantas, productos vegetales, artículos reglamentados, y animales y sus productos; y de velar por el cumplimiento de las normas fito y zoosanitarias del marco jurídico andino.

\section{- Seguridad Alimentaria}

El Acuerdo de Cartagena establece como propósito "alcanzar un mayor grado de seguridad alimentaria subregional" y dispone una serie de acciones para dicho objetivo. En este marco, en la Comunidad Andina se avanza en tres iniciativas complementarias: 1) Programa Andino de Seguridad y Soberanía Alimentaria y Nutricional; 2) Programa Andino de Seguridad Alimentaria en Poblaciones Indígenas; y 3) Proyectos Productivos de Apoyo a la Seguridad y Soberanía Alimentaria.

En el marco del Programa de Seguridad Alimentaria y Nutricional para los Pueblos Indígenas se promueve la recuperación de las prácticas ancestrales de producción, preparación y consumo alimentario, así como de los sistemas de medicina tradicional en comunidades indígenas seleccionadas de los Países Miembros.

Ya para el primer semestre del 2013 se estaban ejecutando 26 Proyectos en diferentes zonas rurales pobres de los países de la Comunidad Andina, en apoyo a la seguridad alimentaria y desarrollo rural de sus poblaciones. Los beneficiarios son pequeños productores, comunidades indígenas, asociaciones de mujeres, entre 
Revista Electrónica de Investigación en Ciencias Económicas

Facultad de Ciencias Económicas, UNAN-Managua

La Comunidad Andina: un paradigma de Integración Económica en Latinoamérica

otros, en las fases de producción primaria, transformación y comercialización de alimentos.

Servicios y competitividad

- Comercio de Servicios

REICE | 15

El Acuerdo de Cartagena establece que la Comisión de la Comunidad Andina aprobará un marco general de principios y normas para lograr la liberación del comercio intrasubregional de los servicios. En tal sentido, al amparo de las Decisiones 439 y 659 , se cuenta con una zona de libre comercio de servicios.

\section{- Transportes}

La CAN ha adoptado una serie de normas comunitarias para facilitar las operaciones de transporte en sus diferentes modalidades y contribuir, en esa forma, al crecimiento del comercio intrasubregional y el fortalecimiento de su integración física. Actualmente, todos los modos de transporte (carretera, aéreo y marítimo), incluyendo el multimodal, poseen normas específicas que establecen, con claridad y precisión, los criterios necesarios para realizar estos servicios. El marco normativo comunitario define pormenorizadamente los términos de contratación, los derechos y las obligaciones del transportista y del usuario (de los operadores en su caso), y las responsabilidades; todo para fomentar la prestación de servicios y garantizar la eficiencia y la protección del usuario.

\section{- Telecomunicaciones}

El sector de telecomunicaciones ha experimentado un rápido crecimiento en los países andinos y, a nivel comunitario, el tema ha ido cobrando importancia. El Comité Andino de Autoridades de Telecomunicaciones (CAATEL) es el órgano comunitario para el diseño y seguimiento de los mecanismos andinos sobre el sector de telecomunicaciones.

Con la Decisión 638 se acordaron los lineamientos para la protección al usuario de telecomunicaciones de la Comunidad Andina. Actualmente, el CAATEL está desarrollando acciones destinadas a promover la integración en telecomunicaciones haciendo énfasis en la mejora del servicio de roaming en zonas fronterizas para reducir sus tarifas y en el intercambio intracomunitario de información sobre los equipos celulares robados para bloquear su servicio en la subregión.

Con el fin de disponer de un sistema satelital para la CAN, los países andinos han aprobado tres normas relevantes: 1) Un marco regulatorio para la utilización comercial del recurso órbita-espectro de los países miembros y los procedimientos para otorgar las autorizaciones comunitarias; 2) El Registro Andino para la autorización de Satélites con Cobertura sobre Territorio de los Países Miembros de 
Revista Electrónica de Investigación en Ciencias Económicas

Facultad de Ciencias Económicas, UNAN-Managua

La Comunidad Andina: un paradigma de Integración Económica en Latinoamérica

la Comunidad Andina; y 3) Una autorización comunitaria a la empresa New Skies Satélites B.V. para la utilización comercial del recurso órbita-espectro de los países miembros en la posición orbital $67^{\circ}$ Oeste.

\section{- Integración Energética}

La CAN ha identificado a la Integración Energética como una de las actividades sustanciales para perfeccionar el mercado ampliado. Hasta el presente, la experiencia de la CAN ha estado concentrada en la elaboración de normativa en torno a la interconexión de los sistemas de electricidad de los países miembros. La interconexión de los sistemas eléctricos entre los países miembros posibilita los intercambios comerciales intracomunitarios de electricidad beneficiando a los ciudadanos andinos en términos económicos, sociales y ambientales.

En la Agenda Estratégica Andina se identificó a la integración energética como una de las áreas clave para el proceso de integración, y se orientan las acciones procurando utilizar de manera óptima sus recursos energéticos y a contribuir a la seguridad y confiabilidad del suministro eléctrico en la subregión.

\section{Estabilidad Económica y Movimiento de Capitales}

\section{- Estabilidad macroeconómica}

Los primeros esfuerzos para la "armonización gradual de políticas económicas y sociales", prevista en el Acuerdo de Cartagena, se dieron desde el inicio del proceso de integración, pero es en 1991 que se inicia el proceso de convergencia macroeconómica al interior de la CAN, cuando el Consejo Presidencial Andino instruye a los ministros del área económica y presidentes de bancos centrales a desarrollar un programa de trabajo para sentar las bases de una armonización gradual de las políticas cambiarias, monetarias y fiscales, que debía promover la estabilidad económica.

Los hechos registrados durante los últimos años, principalmente por los shocks externos negativos, refuerzan la necesidad de llevar a cabo un monitoreo de las vulnerabilidades de las economías andinas, por lo cual se requiere establecer indicadores claves para detectar riesgos actuales y futuros sobre el desarrollo económico y social de los países. En este sentido, el Grupo Técnico Permanente ha definido 19 Indicadores de Vulnerabilidad Macroeconómica Fiscal y Externa, para los cuales se elaboró además una metodología común, tomando en consideración las particularidades de cada economía andina. En 2011 se incluyeron 20 indicadores socioeconómicos; y posteriormente se incluyeron 12 Indicadores referidos a la vulnerabilidad financiera.

El Consejo de Ministros de Hacienda o Finanzas, Bancos Centrales y Responsables de Planeación Económica ha adoptado tres criterios de convergencia respecto de la volatilidad de los niveles de precios y en temas fiscales, los cuales deben ser 
Revista Electrónica de Investigación en Ciencias Económicas

Facultad de Ciencias Económicas, UNAN-Managua

La Comunidad Andina: un paradigma de Integración Económica en Latinoamérica

cumplidos por los países andinos. En mayo de 1999 se adoptó el primer criterio de convergencia en materia de inflación, que consiste en alcanzar gradualmente tasas anuales de un dígito. En junio de 2001 se adoptó un segundo criterio de convergencia en materia fiscal (a partir del año 2002, el déficit del sector público no financiero no exceda del 3\% del PIB). En 2001 se adoptó el tercer criterio de convergencia en materia fiscal, que consiste en lograr que el saldo de la deuda pública explícita (externa e interna) del sector público consolidado no exceda del $50 \%$ del PIB.

Adicionalmente, la CAN adoptó medidas sobre Doble Tributación. La CAN también busca mejorar la integración de los mercados financieros andinos a través del aumento de la eficiencia en el proceso ahorro-inversión (menores costos financieros para el usuario, variedad de instrumentos financieros, mejor manejo de riesgos, impacto positivo en la competitividad).

- Propiedad Industrial

La CAN posee una normativa moderna y completa en materia de Propiedad Intelectual. Forma parte de ella el Régimen Común de Propiedad Industrial (Decisión 486), mediante la cual se regula el otorgamiento de marcas y patentes y protege los secretos industriales y las denominaciones de origen, entre otros. La Decisión 486 aborda aspectos precisos en materia de patentes de invención, diseños industriales, marcas, denominación de origen y competencia desleal vinculada a la propiedad industrial, entre otros aspectos.

Por su parte, el Régimen Común sobre Derecho de Autor y Derechos Conexos (Decisión 351) reconoce una adecuada protección a los autores y demás titulares de derechos, sobre las obras de ingenio, en el campo literario, artístico o científico.

El Régimen de Protección de los Derechos de los Obtentores Vegetales (Decisión 345) protege las nuevas variedades vegetales obtenidas por los fitomejoradores, mientras que el Régimen Común sobre Acceso a los Recursos Genéticos (Decisión 391) regula la obtención y el uso de estos recursos para una participación más justa y equitativa en sus beneficios, ligado a la protección de los conocimientos, innovaciones y prácticas tradicionales de las comunidades indígenas.

\section{- Inversiones}

El régimen común de inversión extranjera garantiza un tratamiento igualitario y no discriminatorio a los inversionistas extranjeros y otorga a los países miembros la libertad de definir sus políticas de inversión a través de sus respectivas legislaciones nacionales.

Por su parte, el régimen de empresas multinacionales andinas contempla medidas para estimular la asociación de inversionistas nacionales en los países miembros, para la ejecución de proyectos de interés compartido y alcance multinacional. 


\author{
Revista Electrónica de Investigación en Ciencias Económicas \\ Facultad de Ciencias Económicas, UNAN-Managua \\ La Comunidad Andina: un paradigma de Integración Económica en Latinoamérica
}

Otras Acciones Complementarias al Proceso de Integración

- Seguridad

En el ámbito del problema mundial de las drogas cuenta con un "Plan Andino de Cooperación para la Lucha contra las Drogas llícitas y Delitos Conexos", que se complementa con la "Norma Andina para el Control de Sustancias Químicas que se utilizan en la fabricación ilícita de estupefacientes y sustancias psicotrópicas". Esto busca evitar el desvío de este tipo de insumos de uso legal por el sector productivo andino a la producción de droga.

Con la "Estrategia Andina de Desarrollo Alternativo Integral y Sostenible", se pretende establecer condiciones elementales para lograr la inclusión socioeconómica de las personas que habitan zonas donde existe producción del arbusto de coca, insumo natural para la producción de la cocaína. De cara al futuro, los países miembros han considerado indispensable contar con una Estrategia Andina frente al Problema Mundial de las Drogas, que establezca una hoja de ruta para el trabajo conjunto y con valor agregado a lo que se hace a nivel nacional, para el período $2013-2019$.

El "Plan Andino para la Prevención, Combate y Erradicación del Tráfico llícito de Armas Pequeñas y Ligeras en todos sus aspectos" busca mejorar la coordinación y generar capacidades para enfrentar esta problemática en la subregión. En ese sentido, se prioriza el establecimiento de mejores registros y bases de datos de armas pequeñas y ligeras para permitir un intercambio de información más fluido, para lo cual se está trabajando en el establecimiento de un instrumento comunitario para armonizar el sistema de marcaje de este tipo de armas.

Como complemento a la lucha contra el crimen transfronterizo, también se cuenta con un "Plan Andino de Lucha contra la Corrupción", que refleja el compromiso de la CAN para combatir la corrupción como requisito indispensable para resguardar el patrimonio del Estado, fortalecer el sistema democrático, consolidar la legitimidad institucional y potenciar el desarrollo integral de los pueblos andinos.

\title{
- Medio ambiente
}

En este contexto, los países que conforman la Comunidad Andina se han propuesto cooperar alrededor de objetivos comunes para conservar y usar sosteniblemente la biodiversidad, afrontar los efectos del cambio climático, promover la gestión integrada de recursos hídricos y contribuir con la reducción del riesgo y del impacto que fenómenos naturales y antrópicos puedan producir en la subregión. Existe naturalmente una normativa vigente bastante copiosa sobre este punto del medio ambiente. La Agenda Ambiental Andina 2012-2016 aprobada por el Consejo Andino de Ministros de Medio Ambiente y Desarrollo Sostenible, un marco de trabajo para el área en los temas de biodiversidad, cambio climático y agua. 


\author{
Revista Electrónica de Investigación en Ciencias Económicas \\ Facultad de Ciencias Económicas, UNAN-Managua \\ La Comunidad Andina: un paradigma de Integración Económica en Latinoamérica
}

Es de destacar las acciones que se han desarrollado en temas como: conservación de los ecosistemas de las regiones andino amazónicas de los países andinos, análisis de los efectos del cambio climático, implementación de medidas de adaptación, apoyo a procesos de fortalecimiento de capacidades para temas relacionados con gestión del riesgo y gestión de información y monitoreo.

REICE | 19

\title{
- MIPYMES
}

El fortalecimiento de las mipymes constituye una de las prioridades de la Comunidad Andina por ser éstas grandes generadoras de empleo, por usar tecnología intensiva en mano de obra y procesar insumos básicamente nacionales. En 2008 se instituyó el Sistema Andino de Estadística de la MIPYME (Decisión 702), que compromete a los países miembros a elaborar y transmitir estadísticas comunitarias armonizadas sobre las pequeñas, micro y medianas empresas.

En 2011 se creó el Comité Andino de la Micro, Pequeña y Mediana Empresa (CAMIPYME), con la misión de asesorar y apoyar a la Comisión y a la Secretaría General de la Comunidad Andina en materias relativas a la política comunitaria sobre la MIPYME, así como en el seguimiento, aplicación y cumplimiento integral del ordenamiento jurídico comunitario en la materia. En 2011 se dispuso la creación e implementación del Observatorio Andino de la MIPYME (OBAPYME) como mecanismo que promueva el desarrollo de la MIPYME en la subregión, el cual debe brindar información actualizada y facilitar el acceso a herramientas de uso práctico e intercambio de experiencias.

\section{- Desarrollo Fronterizo}

La CAN tiene, desde 1999, una Política Comunitaria de Integración y Desarrollo Fronterizo cuyo desarrollo está a cargo del Grupo de Trabajo de Alto Nivel para la Integración y Desarrollo Fronterizo (GANIDF).

Los países andinos dieron en el 2001 un importante paso en este campo al establecer el marco comunitario para la creación de las Zonas de Integración Fronteriza (ZIF) que contienen las normas generales para el establecimiento, funcionamiento y aplicación de controles integrados en Centros Binacionales de Atención en Frontera (CEBAF).

El Banco de Proyectos de Integración y Desarrollo Fronterizo (BPIF) es un mecanismo de apoyo a las Zonas de Integración Fronteriza (ZIF) que tiene como objetivo facilitar la formulación y gestión de proyectos en las ZIF, así como la búsqueda de financiamiento. 
- Turismo

En los últimos años la actividad turística ha registrado un importante desarrollo y crecimiento en los países de la CAN. Así, las llegadas de turistas a los países de la Comunidad Andina pasaron de 2 millones 655 mil llegadas en 2002 a 6 millones en el año 2011.

A nivel comunitario, se cuenta con el Comité de Autoridades de Turismo (CAATUR) y con un Régimen para el Desarrollo e Integración del Turismo, en cuyo marco se han realizado diferentes actividades, entre las que destaca el desarrollo del proyecto Cuenta Satélite de Turismo con el fin de disponer de indicadores armonizados para el seguimiento y evaluación de políticas en la materia. Se ha aprobado también la Agenda para el Desarrollo del Turismo en la Comunidad Andina 2011- 2015, con el objetivo de convertir a la Comunidad Andina en un macro-destino turístico en el mundo, que comprende la facilitación de flujos turísticos desde y hacia los países de la CAN y la creación de productos turísticos innovadores, entre otros.

Asimismo, se ha respaldado las acciones emprendidas por las autoridades aeronáuticas de los países de la CAN con miras a lograr la rebaja de las tarifas aéreas, pues su alto costo limita la competitividad y operación de los productos turísticos andinos; y, se trabaja en fórmulas para lograr la estandarización de la oferta turística de la CAN.

\section{- Circulación de Personas y Migración Laboral}

En 2001 se reconoce los documentos nacionales de identificación como único requisito para viajar por la subregión en calidad de turistas y, en 2006, se aprobó la Tarjeta Andina de Migración como documento uniforme de control migratorio y estadístico de uso obligatorio, para el ingreso y salida de personas del territorio de los países miembros.

En esta materia se han aprobado normas comunitarias que facilitan la libre circulación y establecimiento de trabajadores bajo relación de dependencia en el territorio andino. En 2003 se adoptó el Instrumento Andino de Migración Laboral que contempla normas para la progresiva y gradual circulación y permanencia de nacionales andinos en la subregión con fines laborales. En 2004 se aprobó el Instrumento Andino de Seguridad Social, que busca garantizar la adecuada protección social de los migrantes laborales y sus beneficiarios. Los países de la CAN deben garantizar la circulación de empleados de las empresas prestadoras, así como los tripulantes de las compañías prestadoras del servicio de transporte.

Se aprobó el Instrumento de Migración Laboral, que permite a los trabajadores andinos gozar de idénticos derechos que los trabajadores nacionales, y normas complementarias que brindan protección adecuada en materia de seguridad social y seguridad y salud en el trabajo a los trabajadores andinos que se desplacen de un 
Revista Electrónica de Investigación en Ciencias Económicas

Facultad de Ciencias Económicas, UNAN-Managua

La Comunidad Andina: un paradigma de Integración Económica en Latinoamérica

país miembro a otro. De cara al futuro, la CAN viene intercambiando ideas respecto a la posibilidad de establecer el reconocimiento mutuo de certificación de competencias laborales, la implementación de la red andina de empleo y el establecimiento de un Estatuto de Migración Andino.

REICE | 21

- Cultura

La afirmación de la identidad cultural y de formación de valores ciudadanos para la integración del área andina es un propósito sustancial de la CAN. En ese sentido, se viene trabajando en el fortalecimiento del sector empresarial vinculado a las industrias culturales, en particular las MIPYMES, además de la elaboración de la cartografía cultural del Amazonas y la consolidación de acciones conjuntas respecto a la protección de bienes culturales a nivel andino e internacional.

- Igualdad de Género \& Étnica

Elaborar programas de armonización de políticas en los campos de la participación de la mujer en la actividad económica y de atención a las etnias y a las comunidades locales es otra de las responsabilidades establecidas en el Acuerdo de Cartagena. En la CAN se trabaja de manera conjunta para consensuar una fórmula andina sobre la no discriminación en razón de género en el ámbito laboral y en la determinación de los lineamientos de política sobre los derechos de los pueblos afrodescendientes y las nacionalidades indígenas.

Impacto Económico de la Comunidad Andina

La CAN es el segundo bloque económico del subcontinente, detrás del MERCOSUR, con un $37 \%$ de la población del MERCOSUR y un $20 \%$ de su PIB. El intercambio comercial entre los países alcanzó en 2004 un nivel histórico de US\$7,700 millones. Sin embargo, gran parte de este importe correspondió a Venezuela, que aumentó las ventas a sus socios en un $127 \%$, ascendiendo a US $\$ 2,500$ millones. Si bien este aumento se debió al crecimiento de las economías andinas, también reflejó en gran parte el impacto del aumento de los precios del petróleo.

El intercambio comercial de la CAN con la UE representa el $13 \%$ del total del intercambio comercial de la CAN, mientras que el comercio con EUA asciende a un $30 \%$ de ese total. Este intercambio es asimétrico: la UE absorbe el $14 \%$ de las exportaciones andinas, y la CAN el $0,4 \%$ de las exportaciones europeas. La balanza comercial arroja un saldo favorable a la CAN. Las exportaciones andinas se componen principalmente de materias primas y productos de primera transformación, mientras que la UE exporta productos de alto valor agregado. La CAN reunía hasta 
Revista Electrónica de Investigación en Ciencias Económicas

Facultad de Ciencias Económicas, UNAN-Managua

La Comunidad Andina: un paradigma de Integración Económica en Latinoamérica

mediados de 2006 a Bolivia, Colombia, Ecuador, Perú y Venezuela. Desde la salida de Venezuela en abril de 2006, la CAN reúne al $17 \%$ de la población total de América Latina, es decir, 101 millones de habitantes aproximadamente, en un territorio de 3,7 millones de $\mathrm{km}^{2}$ y cuenta con un PIB (PPA) de unos US\$600,291 millones, y un PIB per cápita de US $\$ 5,952$.

REICE | 22

\section{Relaciones Unión Europea-CAN}

La UE y la CAN están vinculados por un acuerdo de diálogo político y de cooperación, firmado en Roma el 15 de diciembre de 2003. Este acuerdo prevé, entre otras cosas, un fortalecimiento de la cooperación para la integración regional y la posibilidad de celebrar acuerdos bilaterales en los ámbitos específicos de interés común. El apoyo de la Unión Europea a los países andinos representaba al 2006 cerca de 150 millones de euros anuales. La aspiración de la CAN ha sido firmar un verdadero acuerdo de asociación que establezca una zona de libre comercio, lo cual se ha convertido en un "objetivo estratégico común" desde la cumbre de Guadalajara de mayo de 2004.

En junio de 2006, se reunió en Quito una cumbre extraordinaria que permitió adoptar un informe conjunto de evaluación sobre la integración regional. Se identificaron cuatro ámbitos prioritarios en los que se espera mejorar: arancel externo común, armonización aduanera, transporte transfronterizo, liberalización de los servicios.

\section{Cooperación Francia - CAN}

La cooperación Francia-CAN se inscribe en el marco de un protocolo de cooperación Francia-CAN firmado en 1999 y está a cargo de la delegación regional de cooperación para los países andinos, que actualmente tiene su sede en Lima. En el año 2006, esta cooperación ascendió a €500,000. La cooperación, que se concreta en acciones de formación y numerosos seminarios, tiene los objetivos siguientes:

$\checkmark$ Fortalecimiento del Estado de Derecho: cooperación en lo judicial y policial: lucha contra el terrorismo, la delincuencia transfronteriza y el narcotráfico.

$\checkmark$ El apoyo a las políticas andinas de integración regional: integración andina y globalización, armonización de las políticas macroeconómicas, fortalecimiento del sistema andino de estadísticas.

$\checkmark$ Consolidación del Sistema Andino de Investigación y Desarrollo. 


\section{Comercio Intracomunitario e Intercomunitario}

Una vez cumplida la primera etapa de la integración comercial en el año 2005, los países andinos han venido trabajando por la consolidación del mercado ampliado y el perfeccionamiento de la Zona Andina de Libre Comercio, profundizando la integración comercial. En consecuencia, se han adoptado una serie de medidas con el fin de contrarrestar los obstáculos a la libre circulación de los bienes al interior del mercado andino. En este sentido, se cuenta con una normativa relativa a origen, aduanas, defensa comercial, calidad y sanidad agropecuaria, la cual es permanentemente actualizada. Simultáneamente, se han venido desarrollando diversos sistemas de información comercial.

Durante los primeros años del proceso de integración, el comercio era incipiente (menos de US $\$ 80$ millones en 1969). Sin embargo, en la década de los noventa el comercio intracomunitario se incrementó de manera importante. Se destaca, asimismo, que si bien el volumen comercializado con el resto del mundo siempre ha superado en volumen a las exportaciones intracomunitarias, éstas últimas han experimentado un comportamiento histórico más dinámico que las exportaciones dirigidas a terceros.

En el período 2009-2012 el dinamismo de las exportaciones intra y extra comunitarias resultó bastante similar. Durante este período las exportaciones intracomunitarias crecieron en un $79 \%$, pasando de US $\$ 5,774$ millones a US $\$ 10,342$ millones; mientras las exportaciones extracomunitarias incrementaron en un $77 \%$, pasando de US $\$ 71,804$ millones a US $\$ 127,373$ millones. 


\section{Exportaciones de la CAN por destino}

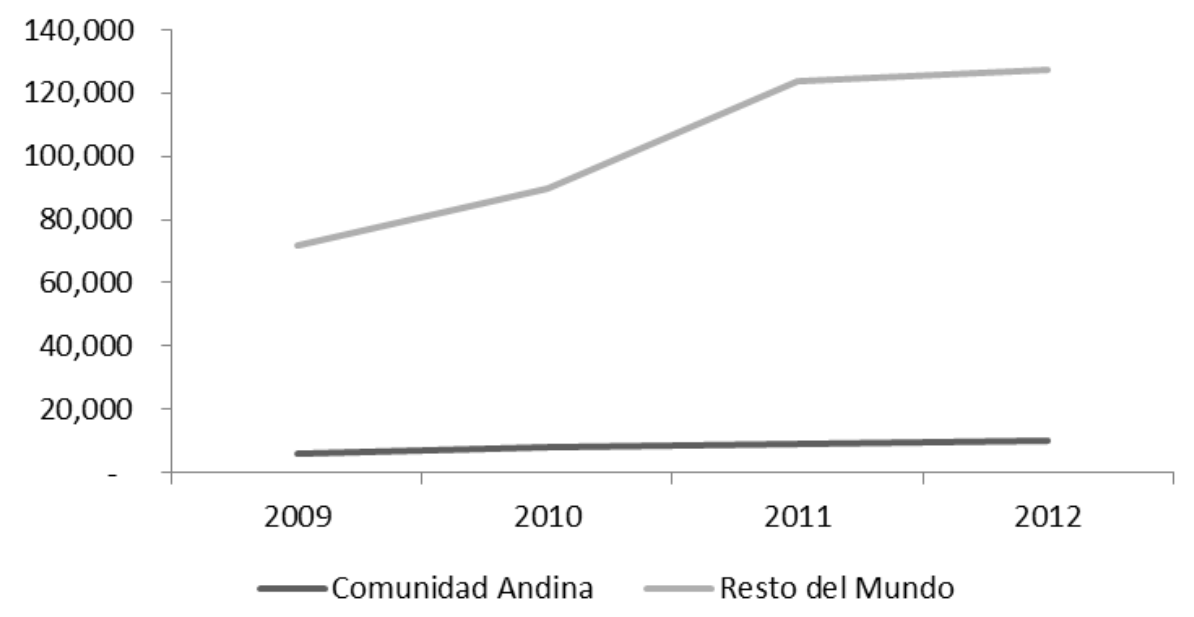

Fuente: Elaboración propia en base a datos de la Secretaria General de la CAN

Cabe destacar que en el año 2009 tanto el comercio de la CAN fue afectado en términos de volumen y precio, principalmente por la crisis internacional que impactó a las economías de la región a través de una disminución del comercio y menores flujos de inversión extranjera directa y remesas, entre otros factores. Las exportaciones a terceros países se vieron mermadas, lo cual se debió principalmente al elevado componente de commodities, cuyos precios internacionales disminuyeron y se registró un menor volumen demandado por los países industrializados, los cuales son el principal destino de las mismas.

Entre los años 2010 y 2012, las exportaciones intra-andinas mostraron una recuperación, alcanzando la cifra récord de US\$10,349 millones en el 2012, con un incremento del $11.77 \%$ con respecto al año anterior. A finales de 2012, Estados Unidos constituyó el principal socio comercial de la Comunidad Andina, siendo destino del $28.27 \%$ de las exportaciones del bloque y el país origen del $21.1 \%$ de las importaciones. Es importante destacar que las exportaciones intracomunitarias se caracterizan por ser una oferta exportable con mayor valor agregado que aquella destinada a países fuera de la subregión ${ }^{3}$. Otra característica importante es que las

\footnotetext{
${ }^{3}$ En el año 2012, el 73\% del comercio intracomunitario está constituido por bienes manufacturados (US $\$ 7,511$ millones), participación que representó más del doble de lo registrado en este sector al inicio del proceso de
} 
Revista Electrónica de Investigación en Ciencias Económicas

Facultad de Ciencias Económicas, UNAN-Managua

La Comunidad Andina: un paradigma de Integración Económica en Latinoamérica

exportaciones intracomunitarias cuentan con una mayor diversificación que aquellas exportaciones dirigidas al resto del mundo (véase anexo 1).

Gráfica No. 2

\section{Balanza comercial de la CAN}

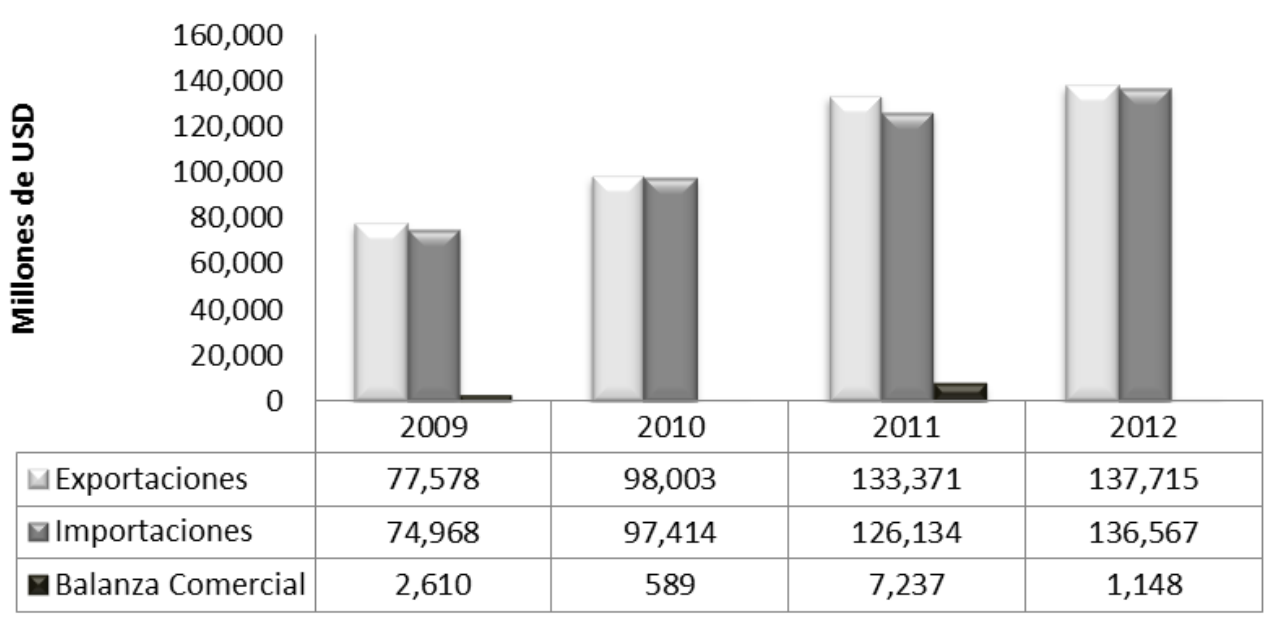

Fuente: Elaboración propia en base a datos de la Secretaria General de la CAN

La balanza comercial intra-andina en los últimos cuatro años se ha mantenido positiva. A nivel interno del bloque ha sido positiva para Bolivia y Colombia, mientras que para Perú ha sido negativa en todo el período. En el caso de Ecuador, fue positiva sólo en años previos (2007 y 2008). El comercio al interior del bloque subregional ha tenido como objetivo la mejora de los procesos de producción a través de la adquisición de experiencia en la elaboración de bienes que facilite la incorporación de mayor valor agregado; ello además de elevar el nivel de exigencia, mejora el estándar de calidad de los bienes que se comercian; es lo que comúnmente se conoce con el nombre de efecto aprendizaje. Asimismo, las exportaciones permiten aumentar la escala de producción, fenómeno que conduce a niveles más eficientes en el proceso productivo. Estos factores permitirían que los productos exportados alcancen un nivel de calidad que les permita competir internacionalmente fuera del bloque subregional en mejores condiciones; lo que se conoce con el nombre de efecto plataforma.

integración (36\%). Para el período 2003-2012, el porcentaje de productos de media y alta tecnología que se exportan intracomunitariamente $(21,6 \%)$, es aproximadamente el cuádruple de aquel exportado a países fuera de la CAN (4.8\%). (Secretaria General de la Comunidad Andina, 2013) 
Revista Electrónica de Investigación en Ciencias Económicas

Facultad de Ciencias Económicas, UNAN-Managua

La Comunidad Andina: un paradigma de Integración Económica en Latinoamérica

Desafíos Económicos y Sociales

La creación de un mercado interino andino es uno de los principales desafíos. Esto comprende la adopción de un arancel externo común (AEC), la implementación de una política agrícola común y la armonización de ciertas legislaciones nacionales.

REICE | 26

Los esfuerzos realizados hasta el momento por los países andinos en estos ámbitos aún no han permitido obtener los resultados esperados. La integración económica andina, que no ha avanzado en la forma deseada, debe hacer frente a dificultades de diversa índole: obstáculos geográficos (barreras naturales, mala navegabilidad de los ejes fluviales), tensiones políticas persistentes, fuertes desigualdades en términos de desarrollo, atracción ejercida por las otras estructuras económicas regionales (EUA, la UE, MERCOSUR) y, recientemente, la salida de Venezuela.

La agenda social cubre temas tales como la educación, la cultura, la formación profesional, la salud, la ciencia y las tecnologías, el desarrollo sostenible, el medio ambiente y la prevención de catástrofes. La Declaración de Machu Picchu sobre la democracia, los derechos de los pueblos indígenas y la lucha contra la pobreza apunta a aumentar la participación de la sociedad civil en el proceso de integración andina.

Conclusiones.

- La Comunidad Andina (CAN) es una comunidad de países que tiene por objetivo común el alcanzar un desarrollo integral, más equilibrado, autónomo, y una cooperación económica y social entre los países miembros. La CAN está compuesta por Bolivia, Colombia, Ecuador y Perú.

- La CAN se inició con la suscripción del Acuerdo de Cartagena, o también llamado Pacto Andino, el 26 de mayo de 1969. El Protocolo de Trujillo y el Protocolo de Sucre modificaron el acuerdo original, e hicieron que se fundara en 1997 la CAN o Sistema Andino de Integración (SAI). Los países del MERCOSUR y Chile son países asociados a la CAN.

- Los principales órganos e instituciones del SAI son el Consejo Presidencial Andino, el Consejo Andino de Ministros de Relaciones Exteriores, la Comisión de la Comunidad Andina, el Tribunal de Justicia Andino, el Parlamento Andino, la Secretaría General y el Banco de Desarrollo de América Latina. Existen también instancias consultivas de la Sociedad Civil. 
Revista Electrónica de Investigación en Ciencias Económicas

Facultad de Ciencias Económicas, UNAN-Managua

La Comunidad Andina: un paradigma de Integración Económica en Latinoamérica

- Luego de establecerse una zona de libre comercio, los países de la CAN han tomado acciones para garantizar entre sí el libre flujo de personas y mercancías. Se ha potenciado el comercio intracomunitario.

- En el período 2009-2012 las exportaciones intracomunitarias crecieron en un $79 \%$; mientras las extracomunitarias incrementaron en un $77 \%$. Hay un leve aumento en la dinámica de las exportaciones intracomunitaria con respecto a las extracomunitarias cuya tendencia puede ir in crescendo.

- Las exportaciones intracomunitarias se caracterizan por ser una oferta exportable con mayor valor agregado y mayor diversificación que aquella destinada a países fuera de la subregión.

- Como proceso de integración regional, la CAN está en una etapa en la que busca pasar de una Zona de Libre Comercio para consolidarse efectivamente en un Mercado Común Regional. La integración económica andina no ha tenido los resultados esperados y presenta serios desafíos.

Bibliografía.

Andina, C. (2010). Portal de la Comunidad Andina. Recuperado el 30 de noviembre del 2013, de: http://www.comunidadandina.org/

Andina, S. G. (2001). Integración y supranacionalidad: soberanía y derecho comunitario en los países andinos. Gráfica Santa Fe: Lima.

Andina, S. G. (2006). La Comunidad Andina, una apuesta por nuestro futuro. Gráfica Santa Fe: Lima.

Comunidad Andina. (s.f.). Recuperado el 30 de noviembre de 2013, de http://www.comunidadandina.org/Resena.aspx

Comunidad Andina. (s.f.). Recuperado el 02 de diciembre de 2013, de HYPERLINK http://es.wikipedia.org/wiki/Comunidad Andina.

Comunidad Andina. (2006). Recuperado el 02 de diciembre de 2013, de HYPERLINK "http://www.diplomatie.gouv.fr/es/fichas-de-paises/america1024/integracion-regional/article/comunidad-andina-de-naciones-can" http://www.diplomatie.gouv.fr/es/fichas-de-paises/america-1024/integracionregional/article/comunidad-andina-de-naciones-can.

BIBLIOGRAPHY V 1033 Dante Antonioli Delucchi. Las leyes del libro en la comunidad andina: Comparación, análisis y comentarios.

Secretaria General de la Comunidad Andina. (2011). Compendio de series estadísticas de la Comunidad Andina: Lima.

Secretaria General de la Comunidad Andina. (2013). Dimensión económino comercial de la Comunidad Andina: Lima. 